\title{
Microscopical Studies of World Trade Center Disaster Dust Particles
}

J.R. Millette, R. Boltin, P. Few, and W. Turner, Jr., MVA, Inc. jmillette@mvainc.com

\section{Introduction}

The terrorist attack and collapse of two towers of the World Trade Center (WTC) in New York City on September 11, 2001 generated tremendous clouds of dust that settled over a wide area. Concern over the potential health effects of breathing this dust made it imperative that the WTC dust be characterized as completely as possible. As part of this characterization, a microscopical examination using several types of microscopes provided key data on the components of the dust. The WTC dust sample that is the primary focus of this report was collected by F.C. Ewing from an outdoor window ledge at 33 Maiden Lane, New York City NY on October 7, 2001.

\section{Equipment and microscopical methods}

The weight of the fibrous fraction (plus attached fine non-fibrous particulate) was determined. The non-fibrous particulate (plus some fiber fragments) was then dry sieved at the following size fractions: $>300 \mu \mathrm{m}, 75-300 \mu \mathrm{m}$, and $<75 \mu \mathrm{m}$. The sample was dry sieved using standard 4 -inch diameter brass sieves (U.S. Standard Sieve Mesh \# 50 and 200). The gravimetric determinations were made in triplicate with a SETRA EZ2-500 electronic 3-place balance.

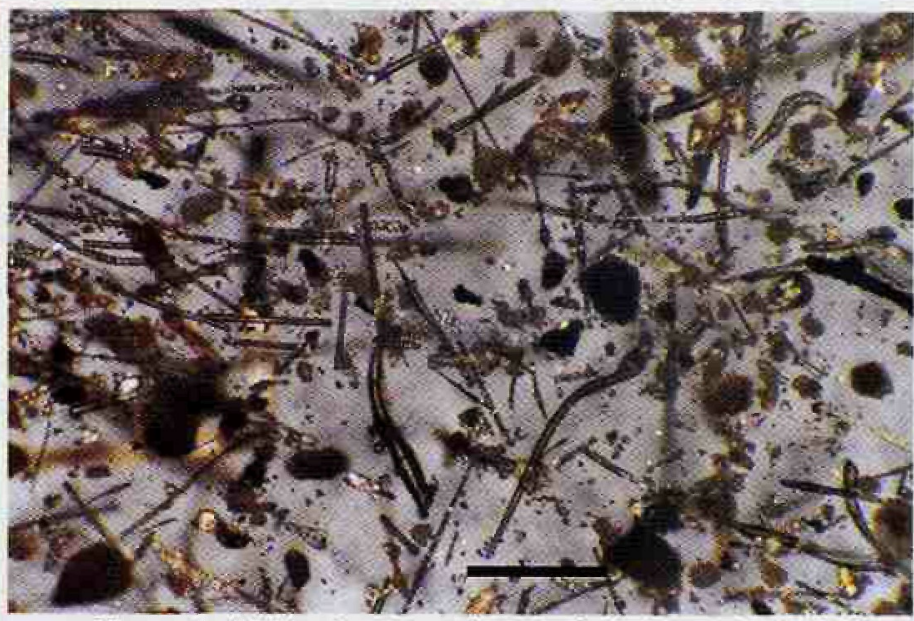

Figure 1. Light microscope image of dust particles on tape from outdoors of 33 Maiden Lane. Glass fibers, cement and plaster are most evident. Bar $=500 \mu \mathrm{m}$

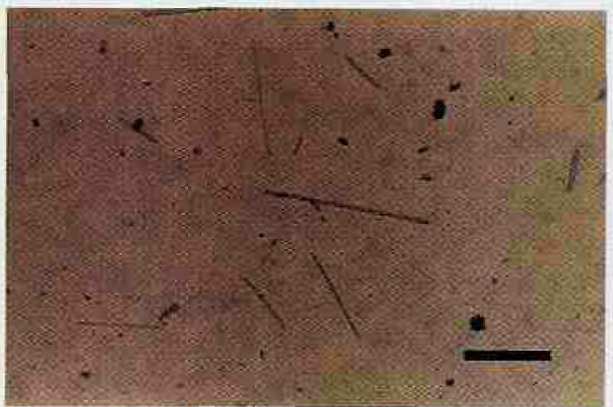

Figure 2. Light microscope image of glass fiber particles and soot aggregates from outdoors of 33 Maiden Lane. The glass (mineral wool) fiber in the center is approximately 1 millimeter long. Bar $=500 \mu \mathrm{m}$.
Macroscopic examination of the sample was conducl wu unu a Zeiss Stemi 2000 stereomicroscope having a magnification range from $6.5 X$ to $47 X$. The sample was then analyzed by polarized light microscopy including microchemical tests utilizing an Olympus $\mathrm{BH}-2$ polarized light microscope having a magnification range from $40 \times$ to $1000 x$. Representative portions from the sample were examined and analyzed by scanning electron microscopy (SEM) using a JEOL 6400 coupled with an $x$-ray energy dispersive spectrometry (EDS) Noran Voyager system. Individual particles from the sample were also analyzed by scanning electron microscopy (SEM) using a JEOL 6500 coupled with an $x$-ray energy dispersive spectrometry (EDS) Noran Voyager system. The fine (small) fractions of the sample were analyzed with analytical electron microscopy (AEM) using a JEOL $1200,100 \mathrm{kV}$ scanning transmission electron microscope (STEM), equipped with a Noran EDS x-ray analysis system. A portion of the sample was also analyzed by Fourier transform infrared microspectrophotometry (micro-FTIR) utilizing a Perkin-Elmer Auto Image System coupled to a Series 2000 FTIR.

The SEM analysis used both the secondary and backscattered modes. For the SEM analysis, portions of the sample was transferred to conductive carbon tape and coated with a thin layer of carbon to provide a conductive surface in the electron microscope. The sample was examined at several magnifications in the secondary (SE) mode. Using the backscattered electron (BE) mode, the sample was examined for particles that contained heavy elements. This procedure is useful in locating particles containing toxic metals such as lead and cadmium. X-ray elemental analysis by energy dispersive spectrometry (EDS) was performed on each particle located for further study by either the BE or SE scans.

The fine (small) fraction of the sample was prepared following the ASTM D6602-00 procedure (1). Briefly, this procedure involves suspending the dust in chloroform and placing a drop of the suspension on a carbon-film TEM grid. The grid was analyzed by TEM for soot and to characterize the particles with diameters less than $2.5 \mu \mathrm{m}$. Fine particles in the air, those with diameters less than $2.5 \mu \mathrm{m}$, are known to be related to long term health effects (2). In 1997 the USEPA set a national ambient air quality standard for fine particulate matter $\left(\mathrm{PM}_{25}\right.$ ) at $15 \mu \mathrm{g}$ per $\mathrm{m}^{3}$ as an annual average. For this standard, the samples were collected using samplers that sort the airborne particles based on their aerodynamic characteristics. Larger, heavier particles act differently from small, light particles in an air flow. The measurement is made only by weighing the particulate and no identification of the particles is done. There is interest

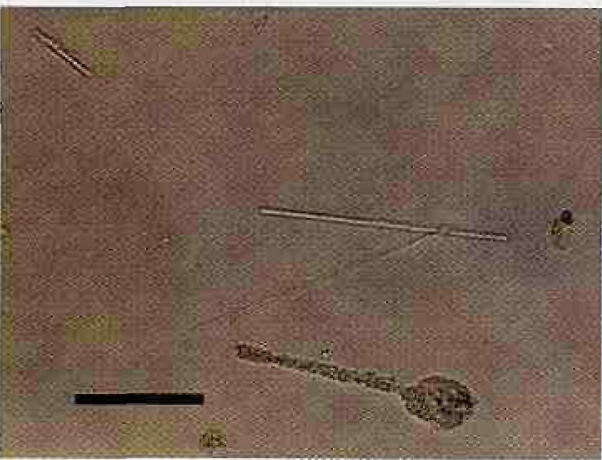

Figure 3. Light microscope image of glass fiber particles and cement from outdoors of 33 Maiden Lane. The glass fiber near the bottom of the micrograph is coated with cement. The glass (mineral wool) fiber in the center is approximately 0.4 millimeter long. Bar $=200 \mu \mathrm{m}$.

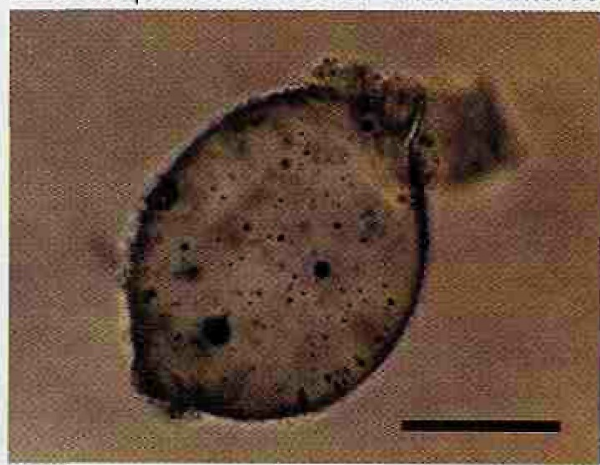

Figure 4. Light microscope image of mineral wool shot from outdoors of 33 Maiden Lane. Diameter of this glass ball is approximately 100 micrometers $(0.1 \mathrm{~mm}) . \mathrm{Bar}=50 \mu \mathrm{m}$ 


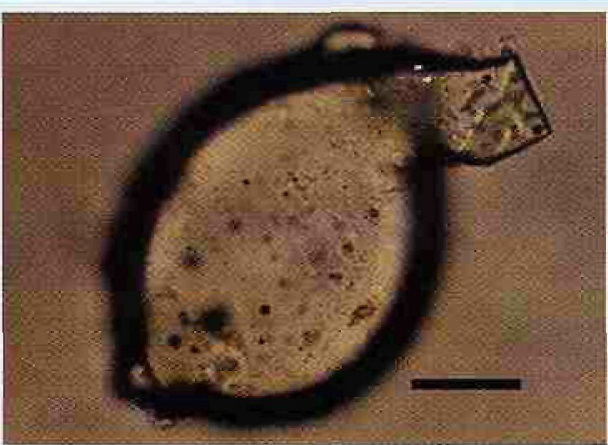

Figure 5. The same mineral wool shot as shown in Figure 4 focused on another plane to show the "tail" of the shot. Diameter of this glass ball is approximately 100 micrometers 10.1 $\mathrm{mm}$ ). Bar $=50 \mu \mathrm{m}$.

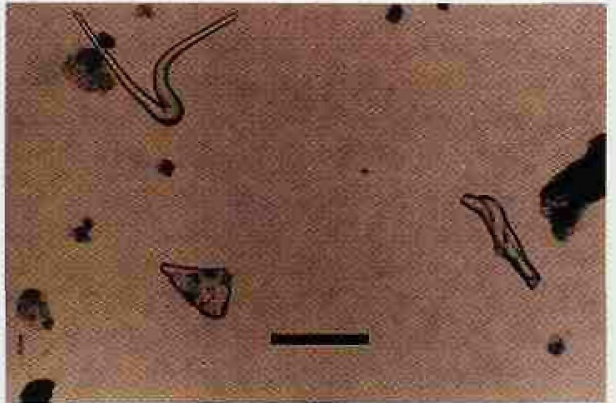

Figure 6. Light microscope image showing two of the more exotic forms of the mineral wool fibers (right and upper left). A triangular glass shard is evident in the lower left area of the micrograph. $B a r=200 \mu m$.

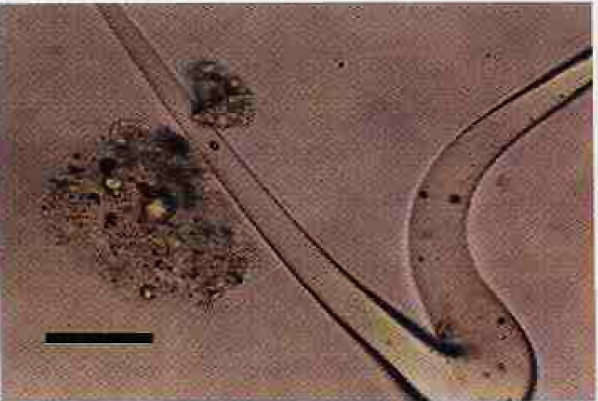

Figure 7. A closer light microscope image of the mineral fiber and cement/ plaster aggregate seen in Figure 6. Bar $=50 \mathrm{\mu m}$.

\section{TABLE I}

\begin{tabular}{|c|c|c|c|c|}
\hline \multicolumn{5}{|c|}{ TABLE I } \\
\hline & \multicolumn{4}{|c|}{$\begin{array}{l}\text { Comparison of Results of Analyses of the Maiden } \\
\text { Lane WTC Sample with Other Analyses of WTC Dusts }\end{array}$} \\
\hline & Column A & Column B & Column C & Column D \\
\hline Sample & Maiden Ln & Maiden Ln & $\mathrm{HP}-02,3$ & L1616 \\
\hline Microscope & Stereo/PLM & TEM & TEM & AutoSEM \\
\hline Preparation & Bulk & ASTM6602 & AHERA & Wet Sieved \\
\hline Number of Particles & All & 400 & 400 & 961 \\
\hline Particle Size Range $(\mu \mathrm{m})$ & All & $0.5-2.5$ & $0.5-2.5$ & $0.5-10$ \\
\hline Mineral wool fibers/shards & $35-40 \%$ & $0.3 \%$ & $0.5 \%$ & $2.6 \%$ \\
\hline Cellulose & $5-10 \%$ & $0.3 \%$ & $0.0 \%$ & NA \\
\hline Chrysotile asbestos & $<1 \%$ & $7.0 \%$ & $5.8 \%$ & * \\
\hline Calcium & Present & $13.0 \%$ & $11.5 \%$ & $7.4 \%$ \\
\hline Plaster / Gypsum & Common & $32.5 \%$ & $41.0 \%$ & $51.8 \%$ \\
\hline Particles consistent with cement & Common & $26.5 \%$ & $14.5 \%$ & $12.9 \%$ \\
\hline $\begin{array}{l}\text { Particles consistent with cement } \\
\text { and gypsum }\end{array}$ & Common & $5.0 \%$ & $5.2 \%$ & $5.8 \%$ \\
\hline Combustion products & Common & $1.3 \%$ & $2.5 \%$ & NA \\
\hline Wood fragments & Present & $0.3 \%$ & $0.0 \%$ & NA \\
\hline Fungal/Biological & Present & $0.3 \%$ & $0.0 \%$ & NA \\
\hline Glass shards & Present & $0.5 \%$ & $1.0 \%$ & $1.4 \%$ ** \\
\hline Si-crystalline (quartz) & Present & $3.0 \%$ & $2.3 \%$ & $1.4 \% * *$ \\
\hline Vermiculite/mica sheets & Present & $2.0 \%$ & $3.3 \%$ & NA \\
\hline Perlite & Present & $0.3 \%$ & $0.8 \%$ & $0.5 \%$ \\
\hline Metal flakes & Present & $2.3 \%$ & $7.5 \%$ & $1.0 \%$ \\
\hline Paint Particles & Present & $0.5 \%$ & $0.8 \%$ & $1.1 \%$ \\
\hline Other - Ca-Si-S fibers & 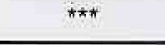 & $3.0 \%$ & $1.8 \%$ & $* \pi n *$ \\
\hline Mixed/Unclassified & Present & $2.3 \%$ & $1.8 \%$ & $16.9 \%$ \\
\hline Total & & $100.0 \%$ & $100.0 \%$ & $100.0 \%$ \\
\hline
\end{tabular}

NA - Not included in the analysis

* $0.6 \%$ of the particles were in a cluster of particles containing mainly $\mathrm{Mg}$ and Si. These could possibly be consistent with talc, chrysotile, or another serpentine mineral. These were included in the unclassified group.

$\star * 1.4 \%$ of the particles analyzed by SEM-EDS were primarily silicon and could be either glass or quartz.

${ }^{* * *}$ Not detected by PLM

${ }^{* \pi * *}$ included in the particles consistent with cement and gypsum cluster in characterizing the composition of the $P M_{2.5}$ and therefore, a preparation of the fine particles was examined by microscopy. The relationship between the less than $2.5 \mu \mathrm{m}$ particles analyzed by microscopy and the particulate matter less than 2.5 aerodynamic diameter $\left(\mathrm{PM}_{25}\right)$ has not been fully researched. However, it has been reported that, "except for very dense materials and clusters, the aerodynamic diameter is very similar to the geometric diameter as might be measured with an electron microscope"(3).

\section{Results}

The fibrous portion of the sample was approximately $10 \%$ by weight. Gravimetric measurements of the sieved sample fractions showed that $18 \%$ of the Maiden Lane WTC dust was $>300 \mu \mathrm{m}, 45 \%$ was between 75 and $300 \mu \mathrm{m}$, and $37 \%$ was less than $75 \mu \mathrm{m}$.

The results of a typical PLM bulk analysis showed that the Maiden Lane WTC dust contained approximately 35 - $40 \%$ mineral wool, $5-10 \%$ cellulose, and less than $1 \%$ chrysotile asbestos (Figures 1-9). The mineral wool composition is shown in Figure 10. The remainder, non-fibrous components as analyzed by PLM, SEM and micro-FTIR, was composed chiefly of plaster, cement particles and combustion products. Some glass shards, charred wood fragments (Figure 11), soil minerals, metal flakes, vermiculite sheets and perlite were present.

Table I shows a comparison of the TEM particle data from the Maiden Lane sample, two other TEM analyses of small WTC dust particles and the Maiden Lane sample PLM bulk analysis. Column A is the bulk analysis of the Maiden Lane sample performed using stereomicroscopy, PLM and microchemical testing. Column $B$ is the TEM analysis from the Maiden Lane sample of 400 particles in the range of $0.5-2.5 \mu \mathrm{m}$ prepared using the procedure described in ASTM method D6602. Column $C$ is the result of a TEM analysis of 400 particles in the range of $0.5-2.5 \mu \mathrm{m}$ prepared from an air sample of WTC dust using 


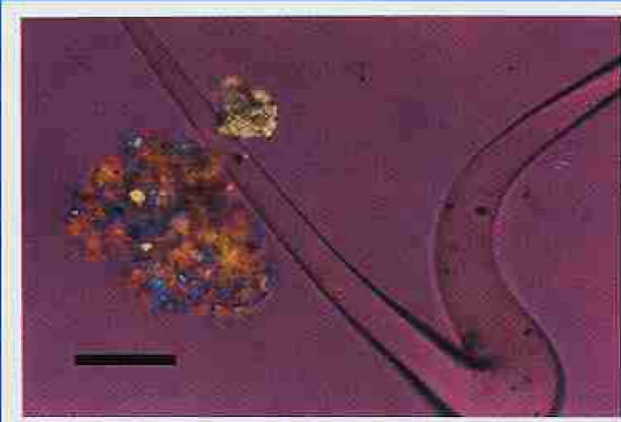

Figure 8. Light microscope image of the same area as seen in Figure 7 . Polarized light with a red plate filter to show the mixture of materials in the aggregate associated with the fiber. Bar $=50 \mu \mathrm{m}$.

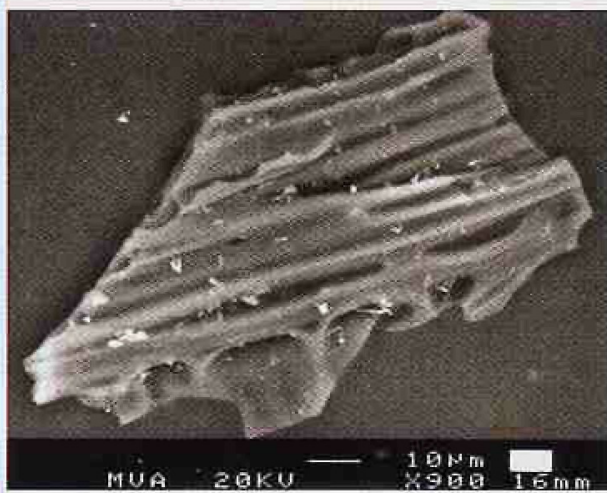

Figure 11. Scanning electron microscope image of a charred wood fragment. Bar $=10 \mu \mathrm{m}$.

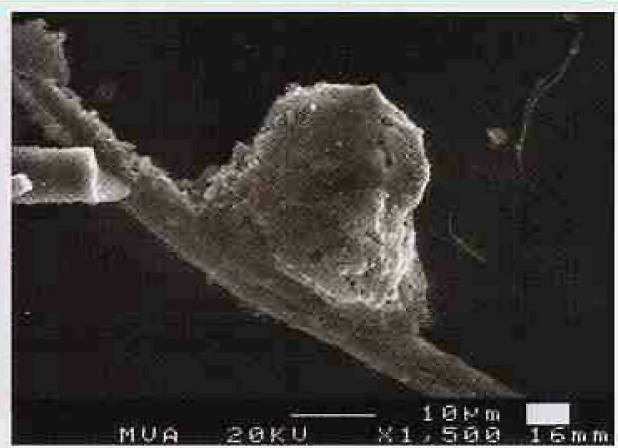

Figure 9. Scanning electron microscope image of cement on mineral wool from outdoors of 33 Maiden Lane. Chrysotile asbestos fibers are evident on the right. Bar $=10 \mu \mathrm{m}$.

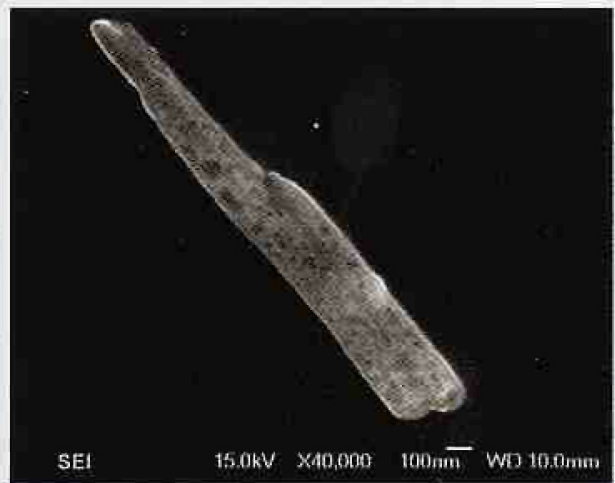

Figure 12. SEM image of a $\mathrm{Ca}$-Si$S$ fiber in the Maiden Lane Sample. (Micrograph by T.B. VanderWood)

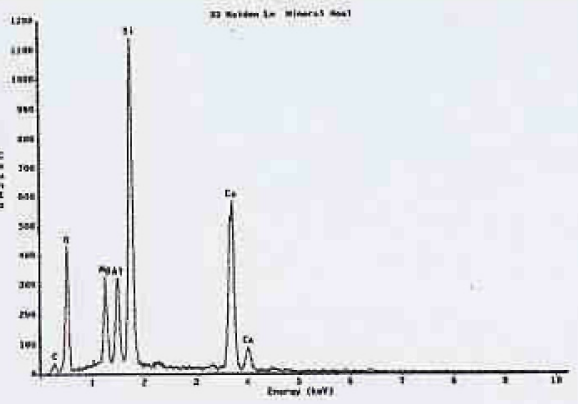

Figure 10. $X$-ray spectrum obtained by SEM-EDS from an uncoated mineral wool fiber.

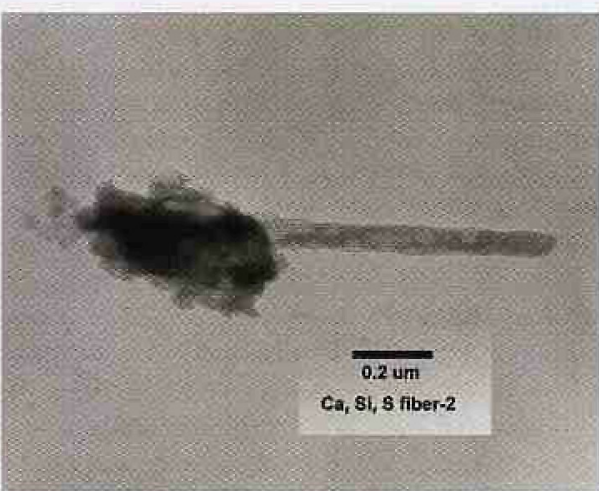

Figure 13. TEM image of a Ca-Si-S fiber in the Maiden Lane Sample.

the direct AHERA preparation procedure (4). The air sample was created by resuspending a sample of WTC dust and collecting the airborne particulate on a 0.4 polycarbonate filter. Column $D$ is the result of an automated SEM-EDS analysis using a dispersion of less than $10 \mu \mathrm{m}$ particles prepared by wet sieving a sample of WTC dust in alcohol through a $10 \mu \mathrm{m}$ pore sized sieve. The particles were dispersed on a polished carbon stub.

The data suggest that the population of WTC particles in the small size range is composed primarily of gypsum particles and cement fragments. Particles of the mineral wool (fibers and frag-

ments) which make up a high percentage of the WTC dust are present only at a trace level $(<1 \%)$ in the range of $0.5-2.5 \mu \mathrm{m}$ and slightly higher in the range of $0.5-10 \mu \mathrm{m}$ range. The automated SEM data is less descriptive than the TEM data because it relied only on the elemental compositions of the particles. Cluster analysis was used to determine the classes of particles found. The TEM analysis provided more information because the operator could distinguish different particle classifications based on morphology and diffraction patterns as well as elemental composition. For example, plates of vermiculite, particles of crystalline silica, and fibers

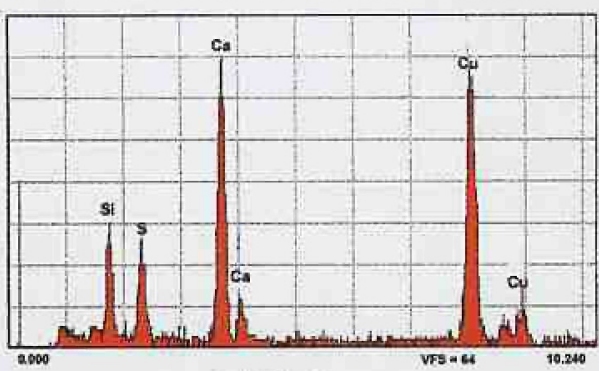

$\mathrm{Ca}, \mathrm{si}, \mathrm{s}$ tiber-2

Figure 14. X-ray Spectrum of a CaSi-S fiber shown in Figure 13. The copper peaks are from the copper TEM grid.

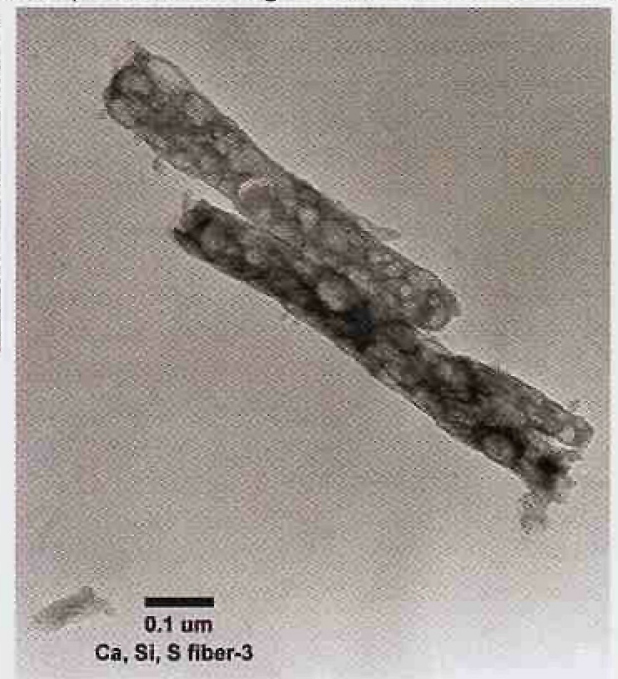

Figure 15. TEM image of a Ca-Si-S fiber in the Maiden Lane Sample.

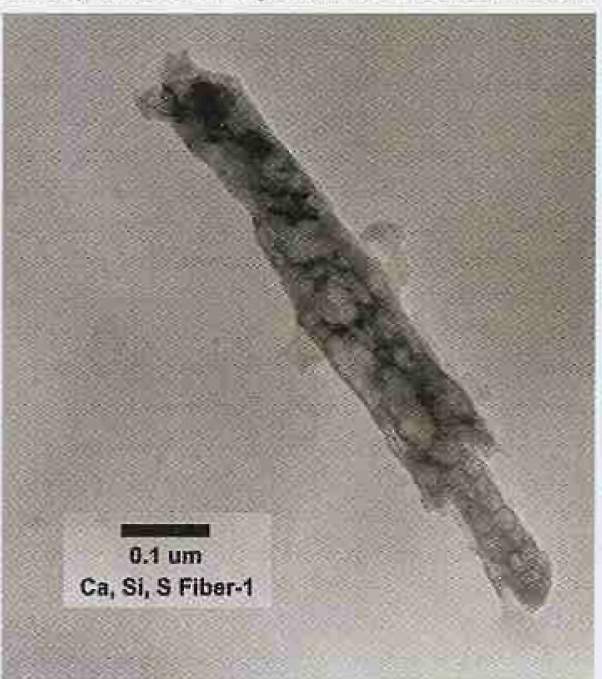

Figure 16. TEM image of a Ca-Si-S fiber in the Maiden Lane Sample. 
of chrysotile were distinguished from other classes of particles with similar chemistries.

In the less than $2.5 \mu \mathrm{m}$ population of particles from the WTC dust samples, one particle type was identified that had not been seen in other dust samples. These were elongated particles composed mainly of calcium, sulfur and silicon with occasionally some aluminum (Figures 12-16). These particles had diameters in the range of $0.1 \mu \mathrm{m}$. With aspect ratios greater than $5: 1$, these particles are considered fibers under the AHERA counting rules. The Ca-Si-S fibers had a distinct morphology; appearing mottled in the TEM image and with a "blistered" image as viewed by the SEM. The particles did not show any evidence of an electron diffraction pattern. The elemental composition of calcium, silicon, and sulfur with occasionally some aluminum was quite different from that of the mineral wool fibers that exhibited an x-ray spectrum of magnesium, aluminum, silicon and calcium.

Discussion

Although it was collected nearly a month after the tragedy, the WTC Maiden Lane dust was found to be very similar to samples of WTC dust collected earlier and examined by the authors and others (5). With the exception of the Ca-Si-S fibers, the constituents of the dust appear to be particles that have been found previously in indoor dust samples. Research is continuing to determine the identity and source of the Ca-Si-S fibers. More of the WTC dust is in the small size range than is seen in other dusts. The percentage of particles less than $75 \mu \mathrm{m}$ in diameter has generally been less than $20 \%$ of the household or office dusts by weight (6). In this WTC dust sample (Maiden Lane) the percentage of particles less than $75 \mu \mathrm{m}$ is $37 \%$. The particles less than $2.5 \mu \mathrm{m}$ are dominated by gypsum and cement fragments. Many of these fragments have small amounts of other elements or materials attached or associated with them.

\section{Acknowledgements}

The authors would like to acknowledge the automated SEM analysis work of Richard Brown. Valeriy Shapiro performed the data cluster analysis. Ron Schott of DCM Science produced the wet sieved fine particle fraction of sample L1616. Lastly, the authors would like to thank William M. Ewing for providing this interesting sample.

References

1. ASTM D6602-00. Standard Practice for Sampling and Testing of Possible Carbon Black Fugitive Emissions or Other Environmental Particulate, or Both. American Society for Testing and Materials (2000).

2. Pope, C. A., Burnett, R. T., Thun, M.J. et al, Lung Cancer, Cardiopulmonary Mortality, and Long-term Exposure to Fine Particulate Air Pollution. J. Amer. Med Association 2002, 287, 1132

3. BeruBe, K.A., Jones, T.P. and B.J. Williamson, Electron Microscopy of Urban Airborne Particulate Matter. Microscopy and Analysis, 1997 26,11-13

4. AHERA - Appendix A to Subpart E - "Interim Transmission Electron Microscopy Analytical Methods", U.S. EPA, 40 CFR Part 763. Asbestos-containing Materials in Schools, Final Rule and Notice. Fed.Reg. (1987) $52(210): 41857$ nี 41894

5. Lioy, P.J., Weisel, C., Millette, J., et al., Characterization of the Dust/ Smoke Aerosol that Settled East of the World Trade Center (WTC) in Lower Manhattan After the Collapse of the WTC September 11, 2002, Environmental Health Perspectives, Vol. 110 , No. 7, 702-714 July2002.

6. Millette, J.R. and T.J. Hopen, "Characterizing Household Dirt: 1928 2001". In: Proc of the Second NSF International Conf. on Indoor Air Health. Jan. 29-31, 2001, Miami Beach, FL

\section{Editor's Note}

This article is republished, with permission, from MICROSCOPE, Vol 50:1, 29-35 (2002).

\section{STOP HASSLING WITH MULTPLE SERVIGE CONTRACTSI}

START by putting all of your instruments under one service contract with MAS (regardless of make or model). Our expert EM SERVICE GROUP has the knowledge and skills to keep your instrument working at its best.

\begin{tabular}{|c|c|c|c|}
\hline \multicolumn{2}{|c|}{ TEM'S / PEM'S } & PREP EQUIPMENT & SPECIAL SERVICES \\
\hline HITACHI & TOPCON & VACUUM COATERS & STAGES \\
JEOL & ISI & PLASMA ASHERS & BEAM BLANKERS \\
AMRAY CAMBRIDGE & $\begin{array}{c}\text { SPUTTER COATERS } \\
\text { ION MILLS }\end{array}$ & CUSTOM DEVICES \\
\hline
\end{tabular}

\section{NEW NEW NEW}

Authorized service representatives for Gatan preparation equipment and Topcon TEM'S.
Contracts and On-Demand

Emergency Service at

Reasonable Rates from

Factory Trained Specialists.

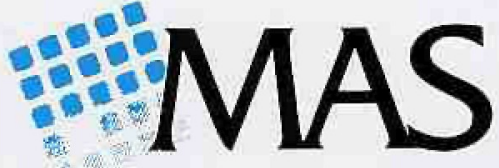

\section{0-421-8451}

3945 Lakefield Cout Suwance, Georgia 30024 770-866-3200 FAX 770-866-3259 616 Hutton Straet Stute 101 Raleigl. North Curolina 27606 919-829-7041 FAX 919-829-5518 ADVANCED ANALYTICAL PRODUCTS AND SERVICES 


\section{EDX \& Imaging Systems}

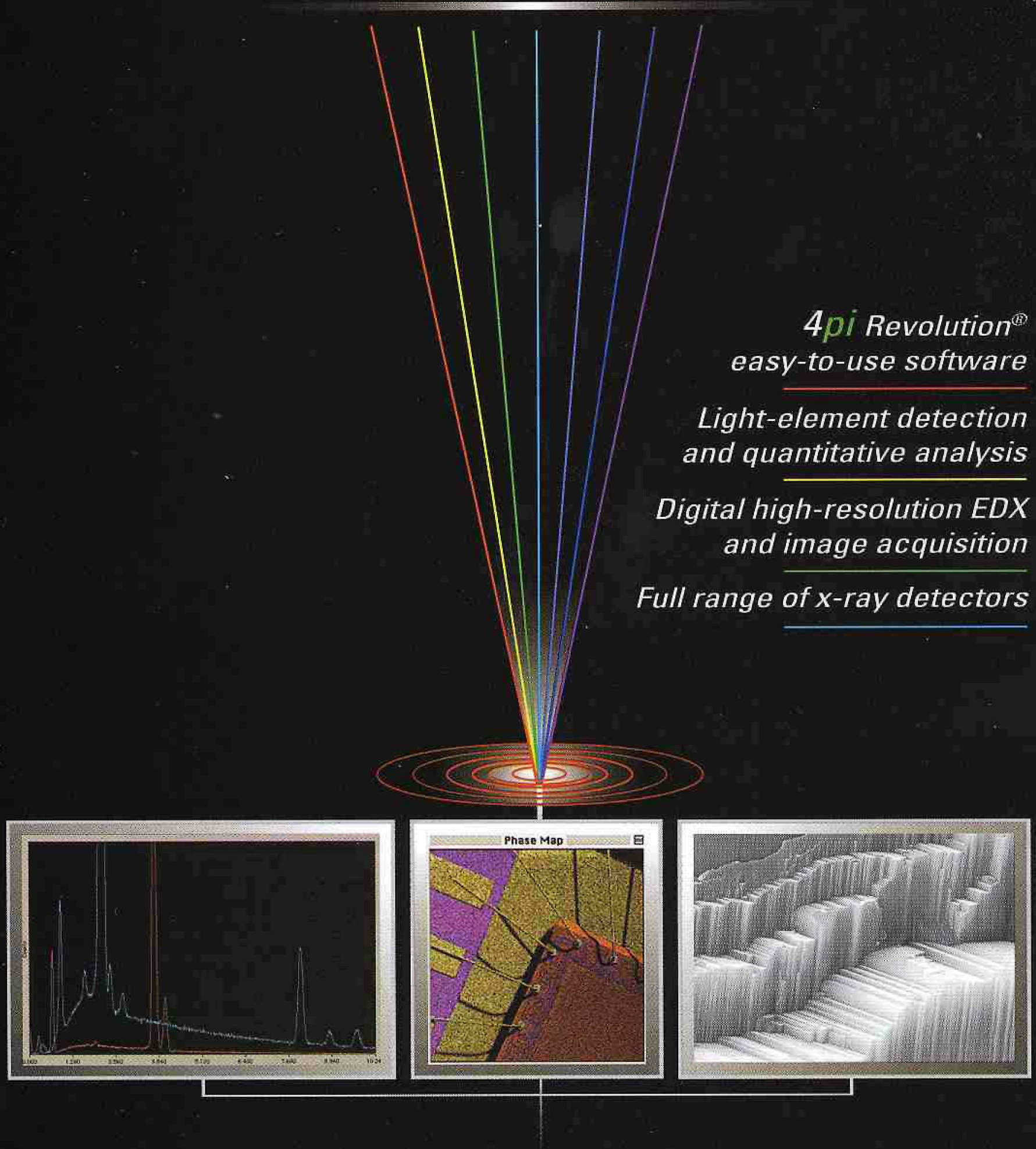

